\title{
Neck pain and low back pain in relation to functional disability in different sport activities
}

\author{
Farzin Farahbakhsh', Maryam Akbari-Fakhrabadi', Ardalan Shariat ${ }^{1, *}$, Joshua A. Cleland ${ }^{2}$, Farbod Farahbakhsh', Tohid Seif-Barghi ${ }^{3}$, \\ Mohammad Ali Mansournia ${ }^{4}$, Mohsen Rostami ${ }^{5}$, Ramin Kordi ${ }^{1,3}$
}

'Sports Medicine Research Center, Neuroscience Institute, Tehran University of Medical Sciences, Tehran, Iran

2Franklin Pierce University, Manchester, NH, USA

${ }^{3}$ Department of Sports and Exercise Medicine, School of Medicine, Tehran University of Medical Sciences, Tehran, Iran

${ }^{4}$ Department of Epidemiology and Biostatistics, School of Public Health, Tehran University of Medical Sciences, Tehran, Iran

${ }^{5}$ Department of Neurosurgery, Shariati Hospital, Tehran University of Medical Sciences, Tehran, Iran

This population-based, cross-sectional study aimed to determine the frequency of neck pain, low back pain (LBP) and also the LBP related functional disability in five sport categories including football, volleyball, basketball, wrestling, and other sports in one of the Iranian sport Olympiads. The prevalence of neck pain and LBP in different time points was evaluated with the use of an interview questionnaire. A visual analogue scale was used to evaluate the athlete's current pain. Furthermore, the functional disability related to LBP was assessed by the Athletes Disability Index Questionnaire (ADI). A total of 452 male athletes aging between 12 and 20 were screened. Three hundred seventy-seven participants responded to the questionnaires in which their mean age (standard deviation) was 15.95 (1.25). Collectively, the life-time prevalence of neck pain and LBP in all the athletes was $38.8 \%$ and $42.0 \%$, respectively. The highest risk of neck pain at all-time points was observed among basketball players compared to other sport groups $(P<0.05)$. The risk of LBP in most time points was the least among wrestlers $(P<0.05)$. The $A D I$ score was significantly higher among basketball players $(13.89 \%)$ compared to volleyball players and wrestlers $(P<0.05)$. Our study revealed a high prevalence of neck pain and LBP among Iranian young male athletes. A higher risk of neck pain and LBP among basketball players predisposes this sport at high risk of developing spine injuries which needs further consideration.

Keywords: Neck pain, Low back pain, Disability, Prevalence

\section{INTRODUCTION}

Neck pain is a widespread disorder with a yearly prevalence of $16.7 \%$ to $75.1 \%$ of the general population (Fejer et al., 2006; Hogg-Johnson et al., 2009; Shariat et al., 2016). However, neck pain in athletes has been less frequently studied in the literature (Noormohammadpour et al., 2016a). According to previous studies, sports with long periods of flexed positions such as cycling are at risk of neck pain (Asplund et al., 2005; Wilber et al., 1995). Similarly, studies on triathletes, have also showed a high life time prevalence of neck pain about $48.3 \%$ due to multiple sports including cycling, swimming and running (Villavicencio et al., 2007). Therefore, the specific type of sport could play a major role in the

occurrence of neck pain. In the study by Jonasson et al. (2011), the prevalence of neck pain in five sports including divers, weightlifters, wrestlers, orienteers and ice-hockey players was compared to nonathletes and no significant difference was observed. Nevertheless, to our present knowledge the comparison of the prevalence of neck pain between different sports has been less frequently examined. Thus, one of the intended purposes of the present study was to compare the prevalence of neck pain in different sports, which could potentially serve as a foundation for guiding us towards better understanding of probable risk factors for sport related neck pain.

In addition to injuries associated with cervical regions, the lumbo-sacral region is also at risk of a high rate injuries with the man-

${ }^{*}$ Corresponding author: Ardalan Shariat (D) https://orcid.org/0000-0002-1877-4747 Sports Medicine Research Center, Neuroscience Institute, Tehran University of Medical Sciences, Tehran, Iran

Tel: +98-9398614772, Fax: +98-2188630227, E-mail: Ardalansh2002@gmail.com Received: April 16, 2018 / Accepted: May 14, 2018 tribution Non-Commercial License (http://creativecommons.org/licenses/by-nc/4.0/) which permits unrestricted non-commercial use, distribution, and reproduction in any medium, provided the original work is properly cited. 
ifestation of low back pain (LBP) (Wójcik and Siatkowski, 2015). The year prevalence of LBP ranges between $22 \%$ and $65 \%$ which is similar to that of neck pain (Fernández-de-Las-Peñas et al., 2013). According to the Global Burden of Disease 2010 study, in the general population, the point prevalence of LBP was estimated $9.4 \%$. LBP results in the highest rate of disability when compared to other disorders (Hoy et al., 2014). The high prevalence of LBP has been reported among different athletes. The overall prevalence rate of about $60 \%$ among football players, field hockey players and speed skaters shows a high number of injuries in athletes (van Hilst et al., 2015). It is plausible that different sports with specific postures could put an excessive load on the lumbar spine. High pressure movements in football and basketball (Pasanen et al., 2016; Tunås et al., 2015), the twisting and landings in gymnastics (Harringe et al., 2007), heavy movements in wrestlers (Granhed and Morelli, 1988), are examples of the underlying mechanisms that may result in the development of LBP.

Besides the direct impact of injuries on health concerns and economic costs, the indirect effect of injuries on the future loss of a young athlete could be irreversible (Ackery et al., 2011). Therefore, assessing the functional disability of professional athletes suffering from neck pain and LBP is a pressing demand in order to best manage injuries and prevent disabilities. Despite the many studies performed on LBP related to disability in the general population, there are few studies examining this issue in athletes. The reason could be due to a lack of an appropriate assessment tool in athletes since the questionnaires used for LBP disability in the general population are not applicable for the athletes as they likely exhibit a ceiling effect. In an earlier observation, our colleagues confirmed the validity and reliability of the Persian version of the Athletes Disability Index Questionnaire (ADI) which has been developed specifically for athletes (Noormohammadpour et al., 2018). Athletes are an underrepresented group in many neck pain and LBP studies, and little has been published regarding the prevalence of neck pain and LBP in athletes especially in Olympiads. Likewise, neck and LBP from previous studies have relied heavily on developed countries. Hence the novelty of this project is in the population being investigated which was among athletes in Iranian sport Olympiads. Iran, as a developing country, has produced elite athletes in the world and in Asia. Consequently, in order to extend this knowledge in other regions of the world we designed the current study on a sport population that has not been reported on to date. Furthermore, according to the above mentioned literature gaps, we aimed to study the frequency of neck pain and LBP and also the level of functional disability in five sport categories including football, volleyball, basketball, wrestling and other sports in one of the Iranian sport Olympiads.

\section{MATERIALS AND METHODS}

\section{Study design}

In this cross-sectional survey, all the 452 male athletes participating in the sport Olympiad entered the study. The age range of the athletes was between 12 and 20 and related medical records were examined to determine the participating sport. This study performed between July and August 2017 in Tehran Province, Iran. The athletes participated in five different sport categories including football, volleyball, basketball, wrestling, and the fifth category was defined as other sports consisting of gymnastic, fitness, shooting, track and field and swimming. The athletes filled in a written consent for their participation. The Ethical Committee of Tehran University of Medical Sciences approved this study by the following Ethic number: 33367-53-04-95.

\section{Screening and data collection}

The screening program for neck pain, LBP, and functional disability was conducted and administered by Sports Medicine Research Center of Tehran University of Medical Sciences.

General information including age, type of sport, training hours spent per week and years involved in a specific sport were obtained via an interview (Shariat et al., 2018). The weight and height of the participants were also measured initially. In order to evaluate the prevalence of neck pain and LBP, a questionnaire was designed based on previous studies (Dionne et al., 2008; Ng et al., 2014). The questionnaire consisted of 40 questions, which were divided into two parts, questions related to neck pain and those related to LBP. A human figure was used for the participants to identify the area of pain (Van den Hoven et al., 2010). Neck pain was defined as a pain between the superior nuchal line and above the spine of scapula which would limit the athlete's routine or sport activities more than one day (Guzman et al., 2009). The definition of LBP was a pain between the lowest rib bone and the lower gluteal fold which would limit the athlete's daily or sport activity more than one day (Dionne et al., 2008). The prevalence of neck pain and LBP including pain at the moment (point-prevalence), the occurrence of pain during the past year (1-year prevalence), during the years spent in the specific sport (sports-life prevalence), chronic pain (the past 3 months) or anytime throughout their life (life-time prevalence) were evaluated by an experienced team of Sports Medicine from our institute using the ques- 
tionnaire. Additionally, a visual analogue scale (VAS) was used to measure the amount of pain felt by the athletes at the time of interview. Prior to the study, a test retest pilot study was performed on 50 male athletes which answered the questions twice within a week apart, and the reliability of the questions were confirmed (intraclass correlation coefficient $>0.9,95 \%$ confidence interval $[\mathrm{CI}])$. In order to evaluate the effect of LBP on functional disability, the athletes were asked to fill out the Persian version of the ADI. The ADI questionnaire consists of 12 questions with 4 answers. The score of each question varies from $0-3$ points $(0$ is related to the first answer and 3 to the last answer). The overall score of 12 questions as percentage is considered as the disability rate of the athlete.

\section{Statistical analysis}

Statistical data analysis was performed with IBM SPSS Statistics ver. 24.0 (IBM Co., Armonk, NY, USA). The quantitative data are presented in mean and standard deviation (SD). The significance of data is considered at $P<0.05$. Regression analysis was used to evaluate the relationship between type of sport and neck pain and LBP. In this study, football had the most participants, therefore for the regression analysis, it was considered as the reference group. Odds ratio (ORs) and 95\% CIs were calculated for all the variables and adjustment was made for age, height, body mass index, and training hours per week. In order to analyze the VAS and ADI scores between sport groups one-way between-group analysis of variance was used.

\section{RESULTS}

As an overall result, 377 athletes filled out the questionnaires with a response rate of $83.4 \%$. The mean age (SD) of the athletes was 15.95 (1.25). Other general information is presented in Table 1.

The highest life-time prevalence of neck pain was attributed to basketball players $(57.69 \%)$ and the highest life-time prevalence of LBP was associated with volleyball players (67.90\%). Furthermore, the lowest life-time prevalence reported for neck pain and LBP was in wrestlers $(18.84 \%, 10.14 \%)$ (Table 2).

Table 3 shows Neck pain and LBP ORs in different sports compared to football at various time periods. According to the results,

Table 1. General information of the athletes

\begin{tabular}{|c|c|c|c|c|c|}
\hline Variable & Football $(n=136)$ & Volleyball ( $n=81)$ & Wrestling ( $n=69$ ) & Basketball $(n=52)$ & Other sports $(\mathrm{n}=39)$ \\
\hline Age (yr) & $16.1 \pm 0.93$ & $15.54 \pm 1.35$ & $16.10 \pm 0.93$ & $16.09 \pm 1.05$ & $15.48 \pm 1.81$ \\
\hline Height (cm) & $174.61 \pm 8.36$ & $175.41 \pm 10.38$ & $174.08 \pm 9.51$ & $176.71 \pm 9.09$ & $165.02 \pm 16.55$ \\
\hline Weight (kg) & $65.14 \pm 11.06$ & $65.46 \pm 12.84$ & $72.94 \pm 15.44$ & $66.40 \pm 13.44$ & $57.16 \pm 18.10$ \\
\hline Body mass index $\left(\mathrm{kg} / \mathrm{m}^{2}\right)$ & $21.31 \pm 2.83$ & $21.15 \pm 3.36$ & $24.02 \pm 5.01$ & $21.17 \pm 3.52$ & $20.93 \pm 5.20$ \\
\hline Training hr/wk & $9.71 \pm 5.68$ & $11.69 \pm 6.94$ & $11.29 \pm 4.64$ & $11.57 \pm 8.22$ & $11.31 \pm 18.85$ \\
\hline Experience in sport (yr) & $5.10 \pm 2.53$ & $2.69 \pm 1.48$ & $3.51 \pm 2.91$ & $3.77 \pm 1.62$ & $4.43 \pm 2.67$ \\
\hline
\end{tabular}

Values are presented as mean \pm standard deviation.

Table 2. Prevalence of neck pain and LBP in various time periods in different sports

\begin{tabular}{|c|c|c|c|c|c|}
\hline Variable & Football $(n=136)$ & Volleyball $(n=81)$ & Wrestling $(n=69)$ & Basketball $(n=52)$ & Other sports $(n=39)$ \\
\hline \multicolumn{6}{|l|}{ Neck pain } \\
\hline Point-prevalence & $10(7.35)$ & $14(17.28)$ & $15(21.73)$ & $19(36.53)$ & $11(28.20)$ \\
\hline Chronic pain prevalence & $13(9.55)$ & $3(3.70)$ & $7(10.14)$ & $7(13.46)$ & $6(15.38)$ \\
\hline 1-year prevalence & $32(23.52)$ & $24(29.62)$ & $7(10.14)$ & $19(36.53)$ & $16(41.02)$ \\
\hline Sports-life prevalence & $33(24.26)$ & $33(40.74)$ & $10(14.49)$ & $24(46.15)$ & $15(38.46)$ \\
\hline Life-time prevalence & $41(30.14)$ & $42(51.85)$ & $13(18.84)$ & $30(57.69)$ & $20(51.28)$ \\
\hline \multicolumn{6}{|l|}{ LBP } \\
\hline Point- prevalence & $9(6.61)$ & $19(23.45)$ & $7(10.14)$ & $13(25.00)$ & $7(17.94)$ \\
\hline Chronic pain prevalence & $12(8.82)$ & $2(2.46)$ & $8(11.59)$ & $8(15.38)$ & $4(10.25)$ \\
\hline 1-year prevalence & $30(22.05)$ & $33(40.74)$ & $6(8.69)$ & $26(50.00)$ & $7(17.94)$ \\
\hline Sports-life prevalence & 42 (33.88) & $39(48.14)$ & $6(8.69)$ & 34 (65.38) & $8(20.51)$ \\
\hline Life-time prevalence & $52(38.23)$ & $55(67.90)$ & $7(10.14)$ & $33(63.46)$ & 11 (28.20) \\
\hline
\end{tabular}

Values are presented as number $(\%)$. 
Table 3. Neck pain and LBP in different sports compared to football in various time periods

\begin{tabular}{|c|c|c|c|c|c|c|c|c|c|c|}
\hline \multirow{2}{*}{ Variable } & \multicolumn{2}{|c|}{ Point prevalence } & \multicolumn{2}{|r|}{ Chronic pain } & \multicolumn{2}{|c|}{12 Months } & \multicolumn{2}{|c|}{ Sport years } & \multicolumn{2}{|r|}{ Lifetime } \\
\hline & $P$-value & OR (95\% CI) & $P$-value & OR (95\% Cl) & $P$-value & OR (95\% CI) & $P$-value & OR (95\% Cl) & $P$-value & OR (95\% CI) \\
\hline \multicolumn{11}{|l|}{ Neck pain } \\
\hline Volleyball & 0.045 & $2.44(1.01-5.87)$ & 0.13 & $0.37(0.10-1.37)$ & 0.26 & $1.43(0.76-2.66)$ & $0.006^{*}$ & $2.28(1.26-4.15)$ & $0.002^{*}$ & $2.49(1.41-4.40)$ \\
\hline Wrestling & $0.004^{*}$ & 3.35 (1.49-8.28) & 0.89 & $1.06(0.40-2.81)$ & $0.024^{*}$ & $0.36(0.15-0.87)$ & 0.10 & $0.52(0.24-1.15)$ & 0.85 & $0.53(0.26-1.09)$ \\
\hline Basketball & $<0.001^{*}$ & 7.25 (3.08-17.08) & 0.38 & $1.54(0.57-4.11)$ & 0.67 & $1.91(0.95-3.82)$ & $0.003^{*}$ & $2.77(1.41-5.45)$ & $0.001^{*}$ & $3.16(1.63-6.11)$ \\
\hline Other sports & $<0.001^{*}$ & $5.4(2.12-13.73)$ & 0.36 & $1.62(0.57-4.57)$ & $0.028^{*}$ & $2.28(1.09-4.76)$ & $0.054^{*}$ & $2.08(0.98-4.38)$ & 0.015 & $2.43(1.19-4.96)$ \\
\hline \multicolumn{11}{|l|}{ LBP } \\
\hline Volleyball & $<0.001^{*}$ & $5.47(2.11-14.20)$ & $0.048^{*}$ & $0.123(0.015-0.97)$ & $0.029^{*}$ & $2.02(1.07-3.83)$ & 0.039 & $1.89(1.03-3.46)$ & $0.001^{*}$ & $3.02(1.59-5.70)$ \\
\hline Wrestling & 0.26 & $1.83(0.63-5.32)$ & 0.56 & $1.32(0.51-3.43)$ & $0.013^{*}$ & $0.30(0.11-0.77)$ & $<0.001^{*}$ & $0.19(0.076-0.48)$ & $<0.001^{*}$ & $0.15(0.064-0.36)$ \\
\hline Basketball & $0.001^{*}$ & $5.34(2.03-14.06)$ & 0.56 & $1.32(0.51-3.43)$ & $<0.001^{*}$ & $3.64(1.78-7.46)$ & $<0.001^{*}$ & $3.97(1.93-8.19)$ & $0.013^{*}$ & $2.48(1.21-5.07)$ \\
\hline Other sports & $0.038^{*}$ & $3.25(1.06-9.90)$ & 0.57 & $1.42(0.40-5.02)$ & 0.71 & $0.83(0.31-2.20)$ & 0.26 & $0.59(0.23-1.47)$ & 0.38 & $0.68(0.28-1.62)$ \\
\hline
\end{tabular}

LBP, low back pain; $\mathrm{OR}$, odds ratio; $\mathrm{Cl}$, confidence interval.

* Significant $P<0.05$ due to binary regression, adjusted by age, height, body mass index, and training hours per week.

Table 4. Mean measurement of VAS for neck pain and LBP and ADI for LBP in different sports

\begin{tabular}{lcccc}
\hline Variable & Football $(n=136)$ & Volleyball $(n=81)$ & Wrestling $(n=69)$ & Basketball $(n=52)$ \\
\hline VAS for neck pain & $0.33 \pm 0.88$ & $0.33 \pm 0.88$ & $0.72 \pm 1.47$ & $1.12 \pm 1.79$ \\
VAS for LBP & $0.20 \pm 0.82$ & $0.60 \pm 1.34$ & $0.29 \pm 0.92$ & $1.10 \pm 2.34$ \\
ADI for LBP & $3.94 \pm 7.03$ & $1.81 \pm 3.96$ & $2.40 \pm 4.66$ & $0.60 \pm 1.34$ \\
\hline
\end{tabular}

Values are presented as mean \pm standard deviation.

VAS, visual analogue scale; LBP, low back pain; ADI, Athletes Disability Index Questionnaire.

Significant $P<0.05$ due to analysis of variance on between group differences.

the highest risk of neck pain in all time points was observed among basketball players compared to other sport groups $(P<0.05$; OR, 1.54-7.25). Additionally, the risk of LBP at most time points was the highest among basketball players. However, the results showed that the life-time risk of LBP was the least among wrestlers $(P<0.001 ;$ OR, 0.064-0.36).

Furthermore the results of the VAS showed that the mean score of VAS for neck pain in basketball players $(1.1 \pm 1.7)$ was significantly higher than volleyball and football players and the mean score of VAS for LBP $(1.1 \pm 2.3)$ in basketball players was significantly higher than other sport groups $(P<0.05)$ (Table 4$)$. The results of the ADI questionnaire showed that the ADI score was significantly higher among basketball players (11.6\%) compared to volleyball players $(P<0.05)$. In addition, the ADI score among football players $(10.95 \%)$ was significantly higher compared to volleyball players $(P<0.05)$.

\section{DISCUSSION}

Neck pain and LBP due to sports are spine injuries which could cause abstinence in competition and substantially affect their pro- fessional life (Mortazavi et al., 2015; Naghdi et al., 2016). We aimed to study the frequency of neck pain, LBP and also the LBP related functional disabilities in five sport categories.

Neck pain in sports is generally often caused by minor ligament or muscle damage (Zmurko et al., 2003). Our study showed that the overall point-time prevalence and life-time prevalence of neck pain in all the athletes was $18.2 \%$ and $38.8 \%$, respectively. In the study of Wilber et al. (1995), the most common injury in cyclists was attributed to the neck with a prevalence rate of $48.8 \%$ (Haldeman et al., 2008). In the study of Villavicencio et al. (2007), the life time incidence of neck pain in triathletes was reported $47.6 \%$ in which $64 \%$ of the neck pain was related to sports. The variation between the prevalence rates of neck pain in our study compared to previous studies could be due to the different type of sports studied. In the literature, less has been reported on neck injuries according to different type of sports, however, studies accomplished so far have been focused mainly on sports with higher complaints of neck pain. For instance, in hockey, the athletes with specific type of postures frequently develop neck pain which makes them at risk of concussions in future years (Schneider et al., 2013) or in football, the act of heading the ball 
could result in degenerative bone injuries in the cervical spine which could lead to long-term defects of the neck (Mehnert et al., 2005).

The current study is one of the first of its kind which has compared different sports regarding pain related to the neck. Our study showed that the highest life-time prevalence and mean VAS of neck pain was in basketball players (57.6\% and 1.1). Basketball similar to other competitive sports relies on the speed and power of the athletes and as the intensity of the competition rises, probability of injuries increases (Riva et al., 2016). The nature of basketball requires controlling a ball while moving which results in repetitive flexed position of the neck which could result in injury. Furthermore high risk of concussion injuries has been reported in female basketball players potentially due to weaker neck ligaments (Agel et al., 2007) which could cause neck and head injuries.

Additionally, the results of the current study showed that the life-time and point-time prevalence of LBP in all the athletes was $42.0 \%$ and $14.5 \%$ respectively with the highest in basketball players (25.0\% and $65.3 \%)$. In a previous study, our colleagues found that compared to other sports, basketball players had the highest life-time and sports-life prevalence of LBP (Noormohammadpour et al., 2016b). Other studies have also shown that among adolescent basketball players, LBP is highly prevalent (Pasanen et al., 2016; Sato et al., 2011). The possible underlying mechanisms could be due to repetitive flexed lumbar movements and sudden rotations during games and training sessions (Noormohammadpour et al., 2016a; Noormohammadpour et al., 2016b). Furthermore, the lowest life-time (10.1\%) and sports-life prevalence (8.6\%) of LBP was contributed to wrestlers. However, previous studies have reported high rates of LBP among wrestlers (59\%). The reason for these differences could be due to the young age of the athletes $(16.68 \pm 2.89)$ in our study and limited years of sport experience, according to previous studies age and also number of active years in a specific sport are positively related to the occurrence of LBP (Çali et al., 2013; Pasanen et al., 2014).

The results of the current study showed that the highest mean percentage of ADI score was related to basketball players (11.6\%) which showed significant higher disability rates compared to volleyball players. In a recent study, Moreira et al. (2016), discovered that sport injuries related to the lower limbs in basketball players may decrease physical and mental levels of quality of life. The results also showed that other sports as a whole including gymnastic, fitness, shooting, track and field and swimming and also football players had higher ADI percentage scores compared to volley- ball and wrestling. Since trunk muscle strength is a predominant factor for disability due to LBP (Iwai et al., 2004), type of sport, training hours and more importantly prevention and management of lumbar injuries by interventions such as neuromuscular warmup (LaBella et al., 2011) can play an important role in reducing disabilities related to LBP.

The present study collected information about the prevalence of neck pain and LBP and disability related to LBP in young male athletes. The findings could be used for initiating clinical guidelines in the prevention and management of spine complications related to sports. However, our study has several limitations first, no control group was defined for the present study and football players were considered as the control group. Second, since the study is a retrospective study, memory bias could have affected the results. Third, only male athletes were recruited for the study and the results could not be generalized to female athletes. Future studies are needed to provide information about neck pain and its correlates in different sports and also further intervention trials in order to prevent and manage disability related to sports.

Taking together, our study indicated a high prevalence of neck pain and LBP among Iranian young male athletes. A higher risk of neck pain and LBP was observed among basketball players and the lowest risk was detected in wrestlers. Furthermore, the highest functional disability related to LBP was seen in basketball players which show this sport is at high risk of developing spine injuries which needs further consideration.

\section{CONFLICT OF INTEREST}

No potential conflict of interest relevant to this article was reported.

\section{REFERENCES}

Ackery AD, Detsky AS; editorial advisory team. Reducing lifelong disability from sports injuries in children. CMAJ 2011;183:1235.

Agel J, Olson DE, Dick R, Arendt EA, Marshall SW, Sikka RS. Descriptive epidemiology of collegiate women's basketball injuries: National Collegiate Athletic Association Injury Surveillance System, 1988-1989 through 2003-2004. J Athl Train 2007;42:202-210.

Asplund C, Webb C, Barkdull T. Neck and back pain in bicycling. Curr Sports Med Rep 2005;4:271-274.

Çali A, Gelecek N, Subasi SS. Non-specific low back pain in male professional football players in the Turkish super league. Sci Sport 2013;28: e93-98. 
Dionne CE, Dunn KM, Croft PR, Nachemson AL, Buchbinder R, Walker BF, Wyatt M, Cassidy JD, Rossignol M, Leboeuf-Yde C, Hartvigsen J, Leino-Arjas P, Latza U, Reis S, Gil Del Real MT, Kovacs FM, Oberg B, Cedraschi C, Bouter LM, Koes BW, Picavet HS, van Tulder MW, Burton K, Foster NE, Macfarlane GJ, Thomas E, Underwood M, Waddell G, Shekelle P, Volinn E, Von Korff M. A consensus approach toward the standardization of back pain definitions for use in prevalence studies. Spine (Phila Pa 1976) 2008;33:95-103.

Fejer R, Kyvik KO, Hartvigsen J. The prevalence of neck pain in the world population: a systematic critical review of the literature. Eur Spine J 2006;15:834-848.

Fernández-de-Las-Peñas C, Alonso-Blanco C, Hernández-Barrera V, Palacios-Ceña D, Jiménez-García R, Carrasco-Garrido P. Has the prevalence of neck pain and low back pain changed over the last 5 years? A population-based national study in Spain. Spine J 2013;13:1069-1076.

Granhed H, Morelli B. Low back pain among retired wrestlers and heavyweight lifters. Am J Sports Med 1988;16:530-533.

Guzman J, Hurwitz EL, Carroll LJ, Haldeman S, Côté P, Carragee EJ, Peloso PM, van der Velde G, Holm LW, Hogg-Johnson S, Nordin M, Cassidy JD. A new conceptual model of neck pain: linking onset, course, and care: the Bone and Joint Decade 2000-2010 Task Force on Neck Pain and Its Associated Disorders. J Manipulative Physiol Ther 2009;32(2 Suppl):S17-28.

Haldeman S, Carroll LJ, Cassidy JD; Bone and Joint Decade 2000-2010 Task Force on Neck Pain and Its Associated Disorders. The empowerment of people with neck pain: introduction: the Bone and Joint Decade 2000-2010 Task Force on Neck Pain and Its Associated Disorders. Spine (Phila Pa 1976) 2008;33(4 Suppl):S8-13.

Harringe ML, Nordgren JS, Arvidsson I, Werner S. Low back pain in young female gymnasts and the effect of specific segmental muscle control exercises of the lumbar spine: a prospective controlled intervention study. Knee Surg Sports Traumatol Arthrosc 2007;15:12641271.

Hogg-Johnson S, van der Velde G, Carroll LJ, Holm LW, Cassidy JD, Guzman J, Côté P, Haldeman S, Ammendolia C, Carragee E, Hurwitz E, Nordin M, Peloso P. The burden and determinants of neck pain in the general population: results of the bone and joint decade 2000-2010 task force on neck pain and its associated disorders. J Manipulative Physiol Ther 2009;32(2 Suppl):S46-60.

Hoy D, March L, Brooks P, Blyth F, Woolf A, Bain C, Williams G, Smith E, Vos T, Barendregt J, Murray C, Burstein R, Buchbinder R. The global burden of low back pain: estimates from the global burden of disease 2010 study. Ann Rheum Dis 2014;73:968-974.

Iwai K, Nakazato K, Irie K, Fujimoto H, Nakajima H. Trunk muscle strength and disability level of low back pain in collegiate wrestlers.

\section{Med Sci Sports Exerc 2004;36:1296-1300}

Jonasson P, Halldin K, Karlsson J, Thoreson O, Hvannberg J, Swärd L, Baranto A. Prevalence of joint-related pain in the extremities and spine in five groups of top athletes. Knee Surg Sports Traumatol Arthrosc 2011;19:1540-1546.

LaBella CR, Huxford MR, Grissom J, Kim KY, Peng J, Christoffel KK. Effect of neuromuscular warm-up on injuries in female soccer and basketball athletes in urban public high schools: cluster randomized controlled trial. Arch Pediatr Adolesc Med 2011;165:1033-1040.

Mehnert MJ, Agesen T, Malanga GA. "Heading" and neck injuries in soccer: a review of biomechanics and potential long-term effects. Pain Physician 2005;8:391-397.

Moreira NB, Mazzardo O, Vagetti GC, De Oliveira V, De Campos W. Quality of life perception of basketball master athletes: association with physical activity level and sports injuries. J Sports Sci 2016;34: 988-996.

Mortazavi J, Zebardast J, Mirzashahi B. Low back pain in athletes. Asian J Sports Med 2015;6:e24718.

Naghdi S, Nakhostin Ansari N, ShamsSalehi S, Feise RJ, Entezary E. Validation of the functional rating index for the assessment of athletes with neck pain. World J Orthop 2016;7:507-512.

Ng L, Perich D, Burnett A, Campbell A, O'Sullivan P. Self-reported prevalence, pain intensity and risk factors of low back pain in adolescent rowers. J Sci Med Sport 2014;17:266-270.

Noormohammadpour P, Hosseini Khezri A, Farahbakhsh F, Mansournia MA, Smuck M, Kordi R. Reliability and validity of athletes disability index questionnaire. Clin J Sport Med 2018;28:159-167.

Noormohammadpour P, Mansournia MA, Asadi-Lari M, Nourian R, Rostami M, Kordi R. A subtle threat to urban populations in developing countries: low back pain and its related risk factors. Spine (Phila Pa 1976) 2016a;41:618-627.

Noormohammadpour P, Rostami M, Mansournia MA, Farahbakhsh F, Pourgharib Shahi MH, Kordi R. Low back pain status of female university students in relation to different sport activities. Eur Spine J 2016b;25:1196-1203.

Pasanen K, Rossi M, Heinonen A, Parkkari J, Kannus P. Low back pain in young team sport players: a retrospective study. Br J Sports Med 2014; 48:651.

Pasanen K, Rossi M, Parkkari J, Kannus P, Heinonen A, Tokola K, Myklebust G. Low back pain in young basketball and floorball players. Clin J Sport Med 2016;26:376-380.

Riva D, Bianchi R, Rocca F, Mamo C. Proprioceptive training and injury prevention in a professional men's basketball team: a six-year prospective study. J Strength Cond Res 2016;30:461-475.

Sato T, Ito T, Hirano T, Morita O, Kikuchi R, Endo N, Tanabe N. Low 
back pain in childhood and adolescence: assessment of sports activities. Eur Spine J 2011;20:94-99.

Schneider KJ, Meeuwisse WH, Kang J, Schneider GM, Emery CA. Preseason reports of neck pain, dizziness, and headache as risk factors for concussion in male youth ice hockey players. Clin J Sport Med 2013; 23:267-272.

Shariat A, Cleland JA, Danaee M, Kargarfard M, Sangelaji B, Tamrin SBM. Effects of stretching exercise training and ergonomic modifications on musculoskeletal discomforts of office workers: a randomized controlled trial. Braz J Phys Ther 2018;22:144-153.

Shariat A, Tamrin SB, Arumugam M, Danaee M, Ramasamy R. Prevalence rate of musculoskeletal discomforts based on severity level among office workers. Acta Med Bulg 2016;43:54-63.

Tunås P, Nilstad A, Myklebust G. Low back pain in female elite football and handball players compared with an active control group. Knee Surg Sports Traumatol Arthrosc 2015;23:2540-2547.

van den Hoven LH, Gorter KJ, Picavet HS. Measuring musculoskeletal pain by questionnaires: the manikin versus written questions. Eur J Pain 2010;14:335-338.

van Hilst J, Hilgersom NF, Kuilman MC, Kuijer PP, Frings-Dresen MH. Low back pain in young elite field hockey players, football players and speed skaters: prevalence and risk factors. J Back Musculoskelet Rehabil 2015;28:67-73.

Villavicencio AT, Hernández TD, Burneikiene S, Thramann J. Neck pain in multisport athletes. J Neurosurg Spine 2007;7:408-413.

Wilber CA, Holland GJ, Madison RE, Loy SF. An epidemiological analysis of overuse injuries among recreational cyclists. Int J Sports Med 1995;16:201-206.

Wójcik M, Siatkowski I. Assessment of spine pain presence in children and young persons studying in ballet schools. J Phys Ther Sci 2015; 27:1103-1106.

Zmurko MG, Tannoury TY, Tannoury CA, Anderson DG. Cervical sprains, disc herniations, minor fractures, and other cervical injuries in the athlete. Clin Sports Med 2003;22:513-521. 